\title{
Development and Application of Biodegradable Materials in E-waste Treatment
}

\author{
Jitendra Rajak \\ SPM College, Udantipuri, Biharsharif, Nalanda, Patliputra University, Patna, India \\ jitendramub@gmail.com
}

\begin{abstract}
Electronic waste also termed as e-waste is one of the utmost rapidly growing sources of waste material along different countries. It is very much hazardous waste mainly consists of discarded electronic and electrical equipment. Most of the emerging countries including India are facing immense challenges associated to the huge generation of e-waste. The management of e-waste in problematic and costly. Illegal importation of e-waste from other countries is also a headache for developing countries. The existing process of e-waste management can cause potential risk to both human health and the environment due to different toxic elements present in e-waste. So, several new ideas should be encompassed with the target to decrease the amount of e-waste generation along with inclusion of biodegradable raw materials in electronics devices manufacturing. Because only biodegradable material can control the release of toxic element to nature. In this report, we have found that these issues should be addressed urgently and some probable solution should be introduced to avoid its harmful future consequences.
\end{abstract}

Keywords: E-waste material, hazardous waste, health risk, biodegradable electronics, solution.

\section{Introduction}

The world is moving faster with advancement of technology. The uses of electronic equipment were increasing day by day at rapid pace with rapid economic growth coupled with urbanization and industrialization. By electronic equipment, we mean products that are linked with either electric current or electromagnetic fields to work. Different circuit's components are also termed as electric and electronic equipment. An e-product becomes electrical and electronic waste (e-waste) when the total product or its specific parts became incapable for their originally intended use without an intention to re-use it [1-3].Devices such as computers, laptops, compact discs (CDs), printers, scanners, fax machines, mobile phones, TVs, iPods, medical instruments, washing machines, refrigerators, air conditioners, etc. and its parts contributes to e-waste. Development of advance new technologies and production of latest models with shorter lifespan is replacing the electronic equipment at lightning speed [4]. Many developing countries like India have more and more problems related to management of e-waste. Instead of being rip to pieces and carefully recycled domestically, a large amount of e-waste is transported from developed to developing countries for dumping [5]. The environmental laws are not maintained in those cases. E-waste anguishes nearly every system of body because e-waste contains different high graded toxic materials, including lead, cadmium, mercury, polybrominated flame retardants, barium, and lithium. The plastic casings used in electronic devices contain polyvinyl chloride (PVC). These toxins can cause several harmful effects such as birth flaws and damage to the organs such as brain, heart, liver, kidney and skeletal system. So, it is risky for our health condition as well as for environment.

The great concern is that when electronic devices are incinerated, buried in landfills, or melted down it possesses great risk to the human health and environment. The more and more electronic products we discard, the environmental and health dangers increase [4,6]. With increases of population, it is very tough to reduce the uses of digital devices. One of the approaches to decrease the quantity of ewaste is recycling. But in the course of recycling procedure the humans engaged in recycling get exposure to hazardous e-waste materials. Sources of exposure to e-waste are of three types: formal recycling, casual recycling, and environmental exposure. In formal e- waste recycling, salvageable materials from out-of-date electronics were once eliminated safely using present day state-of-art equipment. It protects people from adverse health effects. But these facilities are very luxurious and developing nations can't manage to pay for it in massive amount. Informal electronic waste recycling technique retrieve precious elements from waste products with help of primitive techniques, barring developed technology or protecting equipment. As a result, emission of hazardous chemical substances happens. Because of the excessive degrees of environmental, food, and water contamination, residents dwelling inside the periphery of e-waste recycling areas are additionally at remarkable threat of environmental exposure, even though at decrease ranges than occupational exposure[7-11].Thus, appropriate administration is essential whilst disposing or recycling e-wastes. The main problem with e-waste is managing it in proper way. If we can decrease the amount of e-waste at starting point then the problem can be tackled in more concise way. In this paper we have tried to propose some answer which can assist us to control the e-waste recycling alongside with reducing the possible threat to each human health and the environment.

\section{Impact of e-waste on mankind}

There is extreme confusion over the difference between the term "commodity" and "waste" in regard of electronic products. Several research endorse that near about 44.7 to 50 Mt of e-waste are produced all over the world per year which is nearly equals to $6.1 \mathrm{~kg}$ per inhabitant. E-waste is predicted to grow to $52.2 \mathrm{Mt}$, or $6.8 \mathrm{~kg}$ per inhabitant inside 2021-2022 [12]. High production costs and low levels of 
recycling procedure outcomes in accumulation of waste electrical and digital equipment (WEEE) in the environment, in accumulation of pollution. Another most vital problem is that the consequences of incorrect disposal of e-waste are located typically after a lengthy period of time. When a discarded electronic system is disposed of with all its perilous factors implanted in it, hazardous health and environmental results are observed after a huge quantity of time. So, with time the actual danger of the wastes intensifies [4].

In Indian Scenario, IT sector and electronics industry has arisen as the fastest rising section in terms of production, exports and imports. According to different information, the annual growth of IT sector including software industry is about $43 \%$ between the years 1995 to 2008 [13].Others report also confirms the above information. The generation of e-waste creates problem for both human and environment. So, we need to recycle them in order to get back the precious metals used in the electronic and electrical equipment along with saving human health and environment. But in country like India the problem persist in recycling process also. According to specific survey, $95 \%$ of the total generated e-waste in India is being recycled in nonformal sector and solely $5 \%$ of them are dealt with in formal way. Non-formal gadgets commonly accrued e-waste from the rag pickers, then disassembled their useable parts, components, modules, which are having resell value. Finally, the rest of the material is chemically handled to get better valuable metals existing on it. But as the technique is less advance and low-technological driven, it might also cause leaching of hazardous resources to the environment. So, in non-formal technique as the effectivity is low, recuperation is carried out solely for treasured metals like gold, silver, copper, etc. Some different substances such as tantalum, palladium, cadmium, zinc etc. should no longer be recovered [14-15]. The essential trouble is that the complete end-to-end answer of e-waste recycling is still not reachable in India. So, the effectivity of recycling is low in these developing countries. The different fundamental challenge associated to e-waste is that dumping from developed countries. The essential motives for these kinds of exports are low-priced labour rate and lack of environmental precaution requirements in those developed countries. In this manner the poisonous effluent of the developed international locations would deluge toward the world's poorest nations.

\section{Hazardous effect of E-waste}

Most of the electronic and electrical tools are composed of distinct hazardous aspects amongst which majority are poisonous and have negative effects on human health and the surroundings if not dealt with appropriately. Improper recycling manner and disposal strategies which are much more common exercise in the developing nations like India makes these waste greater hazardous for environment. ewastes that are land filled produces filthy leachates which eventually pollute the groundwater. Also, acids and sludge that are acquired throughout melting of pc chips, if disposed on the ground surface can motives acidification of soil. Ewaste recycling can reason acute water shortages as poisonous elements pollute water resources. Mercury, cadmium, lead, etc. from electronic devices, polychlorinated biphenyls (PCBs) from condensers may also leach into the soil and groundwater. When e-wastes are exposed to fire, distinct metals and chemical substances, such as tetra chloro dibenzo-dioxin (TCDD), polychlorinated dibenzodioxins (PCDD), polybrominated dibenzo-dioxin (PBDD) and poly chlorinated dibenzo furans (PCDF) can be emitted. The most hazardous shape of burning e-waste is the open-air burning of plastics in order to get better copper and different highly-priced metals. This toxic emission pollutes the environment. Also, incineration of e-waste emits poisonous fumes and gases which in addition pollutes our nearby surroundings. Dumping of e-wastes from developed nations and recycling them in casual strategies is also enormously hazardous for the health of the labours. The labours coming from socio-economic backward category have now not much consciousness in this issue and for that reason they are inclined to distinctive illnesses induced with the aid of poisonous factors existing in e-waste.

\section{Biodegradable Materials}

Biodegradable substances are these substances that can disintegrate over a given time following implantation in the body. Many special phrases have been used to describe them which include absorbable, resorbable and degradable. They are a kind of biomaterial. Biodegradable polymers (BDPs) or biodegradable plastics refer to polymeric substances that are 'capable of undergoing decomposition into carbon dioxide, methane, water, inorganic compounds, or biomass in which the predominant mechanism is the enzymatic action of microorganisms, that can be measured through standardized tests, in a unique duration of time, reflecting accessible disposal condition' biodegradable plastics need to provide advantages for waste administration systems in order to understand an ordinary benefit. The property of polymers to biodegrade is described by using their structure and does no longer rely on the raw material from which they have originated from. For example, merchandise made of polyethylene will now not biodegrade even if they are made from bio-based polyethylene, whilst many aliphatic polyesters, such as polyhydroxyalkanoates, polylactic acid etc. will biodegrade irrespective of the useful resource used for their production. As a consequence, biodegradable polymers can be each bio-based and fossil-based, and their biodegradability will rely on their structure, no longer their origin.

\section{Proposed Solutions}

In India, it has been detected that in most cases, electronic gadgets are stockpiled casually due to the fact of lack of ideal understanding and attention about the detrimental impact of it. Till now there is no appropriate management. Different hazardous electronic junks lie in houses, roadsides, offices, warehouses etc. Commonly, these e-wastes are combined with household wastes and disposed of at landfills without appropriate management. This necessitates implementation of a splendid administration approach along with sturdy laws and regulations. It can be considered that though the facts science revolution befell in An entire shielded administration and handlings policies of e-wastes and that need to be strictly applied via the Government. In the new framework there ought to be complete ban on 
import of e-waste from developed countries. It must also guide about secure disposal of home electronic waste. There should be provision of a tie recycling in with take-back products. Customers should be given some benefits for returning old used products. The Framework must appropriately tackle the problem of reuse and recycling of ewaste. Government at the same time need to encourage funding in formal recycling area and sufficient modern-day technologies should be inducted in this sector. Different cognizance packages need to be geared up to aware mass and education possibility for e-waste managing to the generators is fundamental in this regard. Government might also additionally introduce tax advantages for scrap provider for appropriate handling and management.

Apart from imposing regulation and law for managing we waste we can additionally limit the impact of e-waste via altering some manufacturing technique. If we can inspire electronic device producer to manufacture their product with fewer toxic ingredients [9]. This can be achieved by using dual approach, one by using training manufacturer to observe this notion and other by using making aware purchaser to purchase low poisonous based products. Some ranking like electrical star ranking may additionally be added to mark product which have low toxic constituents. Also, product need to be designed in such a way that recycling, upgrading and disassembly can be completed easily.

A new notion is additionally treasured in manufacturing digital units is that biodegradable digital elements. Biodegradable electronics is turning into extra and greater famous in coming decades. Once we can graph digital devices with biodegradable electronics raw material then the hazardous impact of e-waste in surroundings and fitness of human beings will be decreased exponentially. This will assist us to fight the issues generated from e-wastes. So, devices made with biodegradable materials can only decreases the wastage of electronic devices and that will not hamper environment as well as human health.

\section{Conclusion}

Electronic waste or e-waste is becoming very serious problem at both local and global levels. e-waste problems appeared primarily as a problem of developed countries but latter extended in other developed countries such as India. The volume of amount of e-waste is growing fast due to rapid change in technology and innovation. The hazardous effect of toxic e-wastes is real threat to both environment and human health. So we need proper handling and management strategy to combat the problems of e-waste. Many research and study are going all over the globe to mitigate the problems of e-waste. The problems of developing countries like India have several problems than developed nations. The import of e-waste from other countries, poor technology of recycling, lack of awareness among populations make the situation more difficult. So there should be strict management's law to combat these situations. Government should organize different programs to raise awareness of the impact of e-waste pollution of both users and manufacturers. Along with that new policies must be introduced and implemented for e-waste management and production of e-waste. Upgradation of old devices and take back of unused devices will also reduce the e-waste amount. Another way to reduce them is to manufacture electronics products with help of biodegradable electronic raw materials. So, devices made with biodegradable materials can only decreases the wastage of electronic devices and that will not hamper environment as well as human health. We need more investments and awareness to fulfill these policies.

\section{Acknowledgments}

The authors acknowledge the Patliputra University for their support for this research work.

\section{References}

[1] Plepiene, J.M. and Youhanan, L. (2019), E-waste and Raw Materials: from Environmental Issues to Business Models, IVL Swedish Environmental Research Institute.

[2] Shagun, Kush, A. and Arora, A. (2013), 'Proposed Solution of e-Waste Management', International Journal of Future Computer and Communication, 2(5), 490-493. DOI: 10.7763/IJFCC.2013.V2.212.

[3] Freemn, M.H. (1989), Handbook of Hazardous Waste Treatment and Disposal, McGraw-Hill Company,USA,

[4] Borthakur, A. Singh, P. (2012), "Electronic waste in India: Problems and policies", International Journal Of Environmental Sciences, 3(1), 353-362. DOI: 10.6088/ijes.2012030131033.

[5] Terada, C. (2012), "Recycling Electronic Wastes in Nigeria: Putting Environmental and Human Rights at Risk”, Nw. J. Int'l Hum. Rts., 10(3), 154-172.

[6] Vallero, D.A. (2005), National Exposure Research Laboratory, U.S. Environmental Protection Agency, Research Triangle Park, North Carolina. DOI:https://doi.org/10.1036/1097-8542.YB050300 2005.

[7] Wong, C.S. Duzgoren-Aydin, N.S. Aydin, A. and Wong, M.H. (2007), "Evidence of excessive releases of metals from primitive e-waste processing in Guiyu, China" , Environ Pollut.,148(1), 62-72. DOI: 10.1016/j.envpol.2006.11.006.

[8] Wong, C.S. Wu, S.C. Duzgoren-Aydin, N.S. Aydin, A. and Wong, M.H. (2007), "Trace metal contamination of sediments in an e-waste processing village in China", Environ Pollut., 145(2), 434-42. doi: 10.1016/j.envpol.2006.05.017.

[9] Schluep, M. Hagelüken, C. Meskers, E.M. Magalini, F. Wang, F. Müller, E. Kuehr, R. Maurer, C.and Sonnemann, G. (2009), "Market potential of innovative e-waste recycling technologies in developing countries. R'09 World Congress; Davos, Switzerland; September.

[10] Yu, X.Z. Gao, Y. Wu, S.C. Zhang, H.B. Cheung, K.C. and Wong, M.H. (2006) "Distribution of polycyclic aromatic hydrocarbons in soils at Guiyu area of China, affected by recycling of electronic waste using primitive technologies", Chemosphere, 65(9), 1500-09. https://doi.org/10.1016/j.chemosphere.2006.04.006.

[11]Fu, J., Zhou, Q. and Liu, J. (2008), "High levels of heavy metals in rice (Oryza sativa L.) from a typical Ewaste recycling area in southeast China and its potential 
risk to human health", Chemosphere 71(7), 1269-75. doi: 10.1016/j.chemosphere.2007.11.065

[12] Shevchenko, T. Laitala K. and Danko, Y. (2019) "Understanding Consumer E-Waste Recycling Behavior: Introducing a New Economic Incentive to Increase the Collection Rates", Sustainability, 11(9), 2656; doi:10.3390/su11092656.

[13] Cherukuri I., Sultana, N. and Podila, S..P. (2018), "Status Of E-Waste In India- A Review", IOSR Journal of Environmental Science, Toxicology and Food Technology (IOSR-JESTFT), 12 (11), 08-16. DOI: 10.9790/2402-1211010816

[14] Pathak, P. Srivastava, R. R. and Ojasvi, (2017), "Assessment of legislation and practices for sustainable management of waste electric and electronic equipment in India", Renew. Sust. Energ. Rev. 78(C) 220-243. https://doi.org/10.1016/j.rser.2017.04.062.

[15] Needhidasan, S. Samuel, M. Chidambaram, R. (2014), "Electronic waste - an emerging threat to the environment of urban India", J Environ Health Sci Eng., 12(36), 1-9. doi: 10.1186/2052-336X-12-36.

[16] Li, R. Wang, L. Kong, D. and Yin, L. (2018), "Recent progress on biodegradable materials and transient electronics”, Bioactive Materials. 3(3) 322-333. 